Textures and Microstructures, 1988, Vols. 8 \& 9, pp. 191-206

Reprints available directly from the publisher

Photocopying permitted by license only

(C) 1988 Gordon and Breach Science Publishers Inc.

Printed in the United Kingdom

\title{
On the Mechanism of Texture Transition in Face Centered Cubic Metals
}

\author{
HSUN HU
}

Department of Materials Science and Engineering, University of Pittsburgh, Pittsburgh, PA 15261, USA

and

R. S. CLINE

Inland Steel Research Laboratories, East Chicago, IN 46312, USA

(Received 23 July 1987)

Dedicated to the memory of Professor Günter Wassermann

It is shown that, if mechanical twinning and deformation faulting on the $\{112\}\langle 111\rangle$ orientation of the rolling texture component are prevented or nullified, such as by cross rolling, the resulting deformation texture is essentially the same for both high-SFE (stacking-fault energy) and low-SFE metals. These observations are consistent with the mechanical twinning mechanism for rolling texture transition from the copper-type to the brass-type as proposed by Wassermann.

KEY WORDS: Cross rolling textures, copper, brass, stainless steel, mechanical twinning, deformation faulting.

\section{INTRODUCTION AND BACKGROUND INFORMATION}

It is now widely known that the deformation textures of the fcc metals are not all the same. They may differ substantially from one metal to another (e.g., aluminum or copper (Hu et al., 1950) vs. silver (Hu and Cline, 1961)), or from a given metal to its alloy (e.g., 
copper vs. the alpha-brasses (Hu et al., 1950; Merlini and Beck, 1955)). For a given metal, similar changes in texture may be effected by varying the temperature of deformation (e.g., copper (Hu and Goodman, 1963), low-zinc brasses (Schmidt and Lücke, 1979), high-purity silver (Hu and Cline, 1961; Hu et al., 1961, or the 304-type austenitic stainless steels (Goodman and $\mathrm{Hu}, 1964)$ ). These textural changes are commonly associated with the apparent stacking-fault energy of the material. The differences in the textures of these materials can readily be observed in all deformation processes, such as in uniaxial or constrained tension including drawing, swaging, or extrusion; in compression or compression rolling; in simple or torsion shear; and in strip or sheet rolling. In the case of strip or sheet rolling, the textural differences are clearly shown by the pole figures of cold-rolled aluminum and 70-30 brass. For the purpose of emphasizing their distinctive characteristics, their (111) and (200) pole figures are both reproduced here side by side in Figure 1 and Figure 2, respectively, for convenient comparison.

\section{(III)}

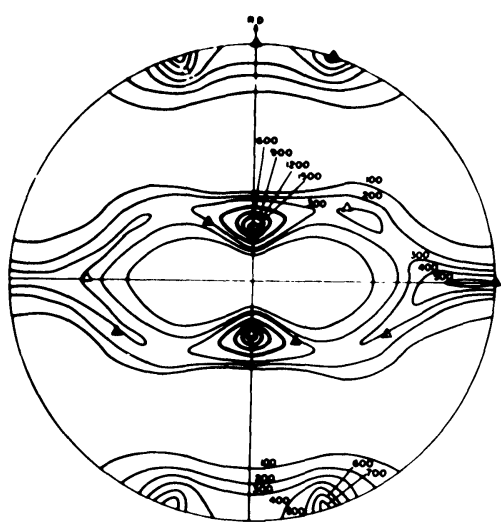

ALUMINUM

(HIGH SFE)
$\Delta(110)$ [i12]

$\Delta(112)[11 i]$

$\Delta(123)$ [iiiz]

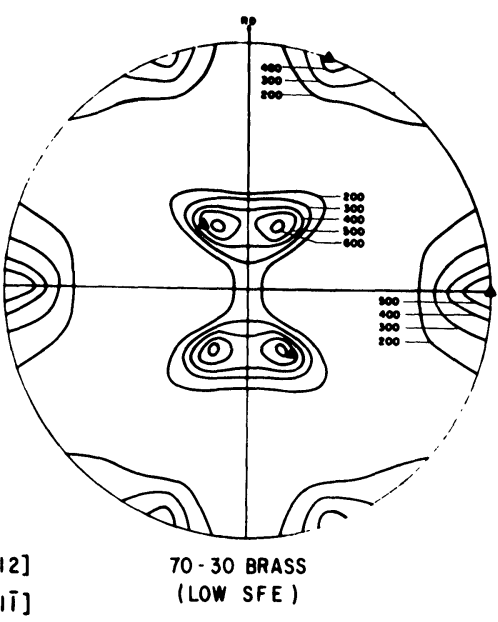

(LOW SFE)

Figure 1 (111) Pole figures showing characteristic differences in the straight rolling textures of fcc metals: commercial purity aluminum (or copper), representing metals with high stacking-fault energy; and 70-30 brass (or silver), representing metals with low stacking-fault energy. 


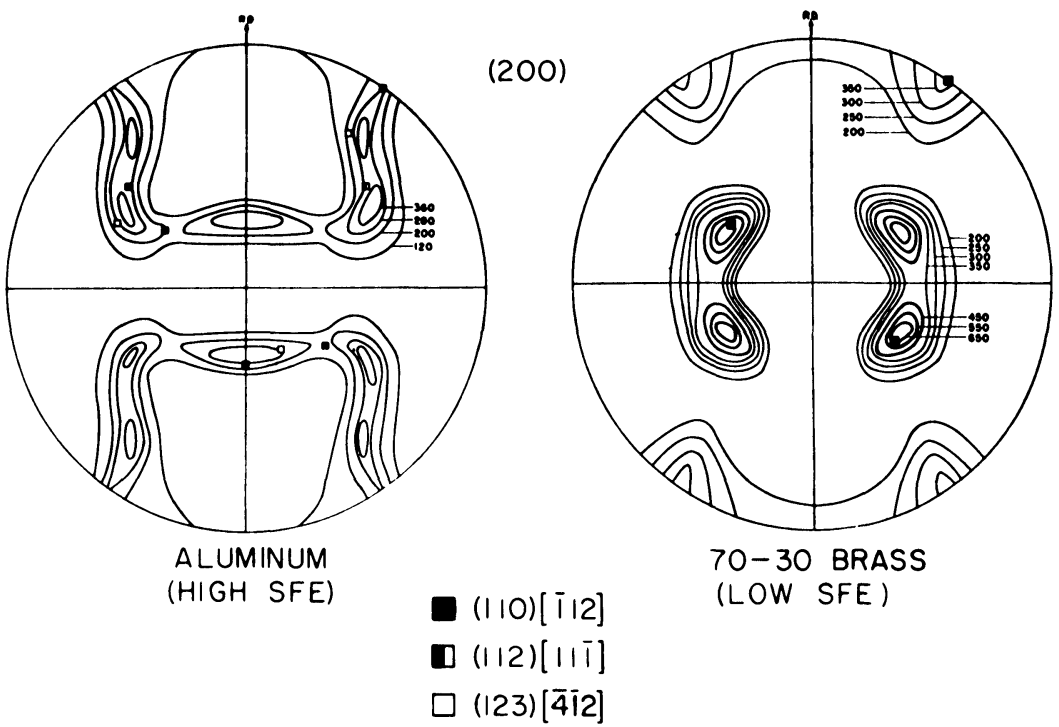

Figure 2 (200) Pole figures of the same specimens used in Figure 1.

As can be noted from Figure 1 and Figure 2, the major characteristic difference between the copper-type (representing the high SFE) and the brass-type (low SFE) textures lies in the prominence of the $\{112\}\langle 111\rangle$ components in the copper-type texture and the absence of these components in the brass-type texture. Other differences, such as a continuous spread from $\{110\}\langle 112\rangle$ to $\{123\}\langle 412\rangle$, including a weak $\{110\}\langle 001\rangle$, may be considered as of a minor nature in comparison.

In regard to the possible mechanisms of such texture transition several theories have been proposed. Among these, Wassermann proposed that the rolling texture of fcc metals can be considered as being composed of two limited fiber textures. One of these has an average orientation of (011)[211] ], the other (112)[11ī]. If mechanical twinning in the systems $\{111\}\langle 112\rangle$ is considered as a possible mechanism of plastic deformation additional to normal slip, then the (112)[111] fiber texture can be converted by twinning to (552)[115], which rotates into the (110)[001] orientation by additional slip. The (011)[211] fiber texture, on the other hand, retains its orientation during deformation, because twinning would lead to 
shape changes that do not meet the strain requirements of the rolling process. A discussion about the various mechanisms proposed was presented by $\mathrm{Hu}$ et al. (1966) with additional new observations on the orientation stability and microstructure of the (112)[11ī] single crystals of high purity copper and its alloy containing $4 \%$ aluminum to attain a low stacking-fault energy. The results of those additional observations were largely in support of the mechanical twinning mechanism as proposed by Wassermann. In addition to mechanical twinning on a microscopic scale, the contribution of profuse deformation faulting, or slip by partial dislocations through the specimen, on lattice rotation of the crystal was also suggested.

\section{PURPOSE OF PRESENT INVESTIGATION}

It was shown previously (Hu et al., 1966) that an analysis of the possible slip systems in a (112)[111̄] crystal during straight-rolling deformation was informative as to its orientation stability, shape change (e.g., the lateral widening of the crystal during deformation), microstructural evolution, and texture development. Figure 3 shows such an analysis with additional features when cross rolling is employed. For the time being, let us ignore rolling in the direction $\mathrm{RD}_{2}$, hence, we are considering straight-rolling a crystal with an initial orientation (112)[111] , i.e., the plane of rolling is (112), and the direction of rolling is [11i]].

The numbers in the parentheses are the Schmid factors calculated on the basis of a biaxial stress system which is an approximation of strip or sheet rolling. The resolved shear stress is thus given by

$$
\tau=\sigma\left(\cos \phi_{t} \cos \lambda_{t}+\cos \phi_{c} \cos \lambda_{c}\right)
$$

where $\sigma$ is the applied stress, $\phi_{t}$ and $\lambda_{t}$ are the angles subtended by the slip plane normal and the slip direction, respectively, with the tension axis (the $\mathrm{RD}_{1}$ ); and $\phi_{c}$ and $\lambda_{c}$ are similar angles made by the same slip elements with reference to the compression axis (the normal direction to the rolling plane). The full-line arrows indicate the direction of rotation of the normal slip vector $\langle 110\rangle$; the dash-line arrow, that of the partial slip, i.e., the deformation faulting or twinning vector, $\langle 112\rangle$. In the absence of deformation 


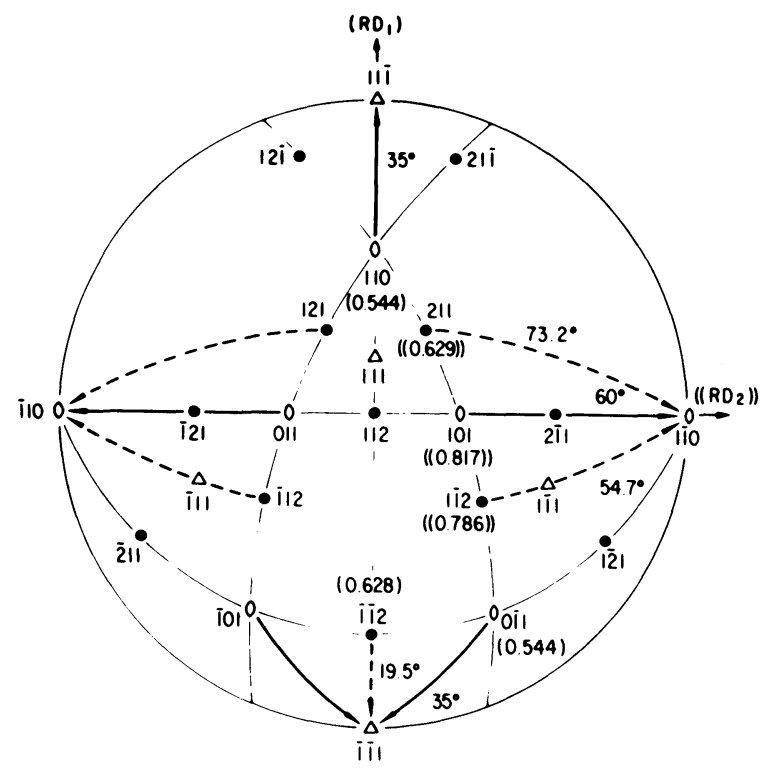

Figure 3 Stereographic projection showing possible slip systems of the (112)[111] crystal in cross rolling deformation. Full-line arrows, normal slip vectors; dashed-line arrows, partial slip vectors (twinning and faulting vectors).

faulting and mechanical twinning (e.g., in the high-SFE materials), normal slip on the coplanar systems of (111)[101] and (111)[011], and on the colinear systems of (111)[110] and (1111)[110], has the self-correcting feature for orientational changes of the crystal during deformation. The self-correcting feature arises from the consideration that these two pairs of slip systems are symmetrically oriented to receive a large shear stress (Schmid factor 0.544 ) by rolling in the (112)[111] ] orientation. If slip occurs accidentally to a larger extent on one of these pairs, such as (111)[110] and (111)[110], the slip direction [110] would rotate along a great circle toward the rolling direction (solid arrow toward $\mathrm{RD}_{1}$ in Figure 3), and the slip plane normals [i11] and [1111] would rotate in a similar manner toward the normal to the rolling plane. Such rotations would result in a continuously decreasing stress on the activated pair of the slip systems, and a continuously increasing stress on the other pair of

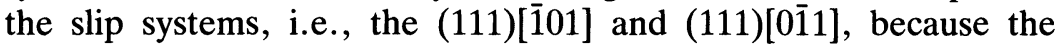


resolved shear stress is maximum when the slip element is oriented at $45^{\circ}$ from both the tension and compression axes in rolling. Hence, at a certain point the (111)[101] and (111)[011] systems will be activated, and the crystal would then rotate in the opposite direction. Thus, the change in orientation of the crystal during deformation by normal slip on these systems is self-correcting. However, if deformation faulting or mechanical twinning on the (111)[1112] system (Schmid factor 0.628) occurs easily in the crystal because the material has a low stacking-fault energy, the selfcorrecting feature of the normal slip and the stability of the crystal would be impaired. The crystal would rotate into a different orientation. The lateral widening of the crystal in rolling would also be minimal because the slip plane normal, [111], and the Burgers vector for faulting or twinning, [1112], are in the plane containing both the tension and the compression axes.

Based on the reasoning as discussed above, one may expect that if the deformation faulting or mechanical twinning on the $\{112\}\langle 111\rangle$ component of a polycrystalline texture is prevented from occurring, or nullified by the deformation immediately following, such as in cross rolling, there should not be much of a difference between the textures developed in a high-SFE and a low-SFE material. As shown in Figure 3, the possible slip systems for the (112)[111] orientation subjected to cross rolling in $\mathrm{RD}_{2}$ are indicated by the double parentheses to distinguish them from those with reference to $R D_{1}$. In fact, when rolling in the direction of $R D_{2}$, the geometry is equivalent to roll with an initial orientation (112)[110]. The Schmid factor is the highest on the duplex systems of normal slip (0.817), which is followed by the systems of partial slip (0.786) and (0.629). However, none of them has a selfcorrecting feature for orientational changes during deformation. The rolling textures of the (112)[110] crystals of copper and aluminum have been reported in the literature (see, e.g., the review portion on the deformation textures of single crystals (Hu et al., 1966). The relevant point to be made here is that the deformation faulting or mechanical twinning on the (111)[1 $\overline{1} 12]$ system (when rolling with the (112)[11i ] initial orientation and in the $\mathrm{RD}_{1}$ direction only) will become completely inactive with respect to the tension axis $\mathrm{RD}_{2}$ in cross rolling. The compressive stresses in the normal direction will not activate this faulting or twinning system because the lateral 
constraints in rolling would not permit such shape changes which lead only to widening. Furthermore, there is no similarly unique faulting or twinning system when rolling is conducted in the $\mathrm{RD}_{2}$ direction. It is, therefore, anticipated that the cross rolling textures of polycrystalline specimens for both high-SFE and low-SFE fcc metals should be largely the same. The purpose of the present investigation was to test this idea by conducting suitable experiments with known materials whose rolling texture transition by alloy addition or by changing the deformation temperature has firmly been established.

\section{MATERIAL AND EXPERIMENT}

\section{Electrolytic copper and $\mathbf{7 0 - 3 0}$ brass}

The polycrystalline texture of electrolytic copper and of 70-30 brass during cross-rolling at room temperature with preselected amount of reductions equally applied in $\mathrm{RD}_{1}$ and in $\mathrm{RD}_{2}$ will be examined. Since it was known from earlier studies (Hu et al., 1966; Goodman and $\mathrm{Hu}, 1968)$ that up to $40 \%$ reduction in thickness the rolling textures of copper and of 70-30 brass were essentially the same, the cross-rolling reductions were, therefore, scheduled as follows:

\section{Rolling schedule A}

1. Roll $40 \%$ in $\mathrm{RD}_{1}$ then roll $40 \%$ in $\mathrm{RD}_{2}$, and examine the texture developed.

2. Roll additional $50 \%$ in $\mathrm{RD}_{1}$, and examine the texture developed.

3. Roll additional $50 \%$ in $\mathrm{RD}_{2}$, and examine the texture developed.

This is the final texture after cross-rolling to a total reduction of approximately $91 \%$.

\section{Rolling schedule B}

In order to balance the plastic deformation in the two rolling directions, $\mathrm{RD}_{1}$ and $\mathrm{RD}_{2}$, more closely, small and equal amounts of 
reduction per pass was employed in successive cross-rolling passes until the final thickness is reached at a total reduction of $90 \%$. Then, the textures of the two materials, corresponding to high and low stacking fault energies, were examined and compared.

As a standard practice, the penultimate material, $6 \mathrm{~mm}$ thick, was carefully prepared from a $25 \mathrm{~mm}$ thick stock by alternate cold rolling (approximately 30\% reduction) and annealing cycles to insure that the starting material had uniformly fine grains $(0.06 \mathrm{~mm}$ for copper and $0.03 \mathrm{~mm}$ for brass) and nearly random texture. For schedule $\mathrm{A}$, the rolling was conducted by reversing end for end between consecutive passes in each of the $\mathrm{RD}_{1}$ and $\mathrm{RD}_{2}$ directions. For rolling schedule $\mathrm{B}$, the reversing effect was brought about by simply turning the workpiece $90^{\circ}$, always in the clockwise (or anticlockwise) direction after each pass. A light oil was applied to the surfaces of the workpiece to reduce the frictional forces in rolling. The actual reduction sequence was approximately as follows: $0.15 \mathrm{~mm}$ per pass to $3.6 \mathrm{~mm}, 0.10 \mathrm{~mm}$ per pass to $2.2 \mathrm{~mm}$, $0.05 \mathrm{~mm}$ per pass to $1.1 \mathrm{~mm}$, and $0.025 \mathrm{~mm}$ per pass to $0.55 \mathrm{~mm}$. In terms of strain, it ranged from 0.025 to 0.045 per rolling pass. One could, of course, use a reduction schedule based on constant strain, instead of constant reduction, but this would require tedious adjustments of the roll opening after every pass. With such a small range of strain $(0.025$ to 0.045$)$ in the reductions per pass actually employed, the effect of imbalance in deformation between $\mathrm{RD}_{1}$ and $\mathrm{RD}_{2}$ should be minimal.

For texture examinations, complete pole figures were determined from the midthickness section of the strip. Filtered $\mathrm{CoK}_{\alpha}$ and $\mathrm{MoK}_{\alpha}$ radiations were used for measuring the diffracted intensities by the reflection and transmission techniques, respectively. The intensities were expressed in units of the random intensity measured from a copper powder specimen.

\section{Type 304 austenitic stainless steel}

It was shown in an earlier investigation that the rolling texture of the 18-8 stainless steel (type 304 or $304 \mathrm{~L}$ ) changes from the brass-type to the copper-type by increasing the deformation temperature. Rolling the steel isothermally at $200^{\circ} \mathrm{C}$ to $90 \%$ reduction produced a brass-type texture, which could hardly be differentiated 
from that of a 70-30 brass. Similarly, by isothermal rolling the steel at $600^{\circ} \mathrm{C}$ or higher (e.g. $800^{\circ} \mathrm{C}$ ) a copper-type texture was produced. In the present investigation, the cross-rolling textures of a commercial stainless steel, type 304 , isothermally rolled $90 \%$ at $700^{\circ} \mathrm{C}$ and at $200^{\circ} \mathrm{C}$, were also studied. The experimental procedures as described for copper and brass were followed closely. The penultimate material, $6 \mathrm{~mm}$ thick, had an average grain diameter of $0.03 \mathrm{~mm}$, and the initial texture was nearly random. The isothermal rolling was conducted by reheating the workpiece after each pass to the desired temperature, which took about 2 and 5 minutes for restoring the rolling temperatures, 200 and $700^{\circ} \mathrm{C}$, respectively.

For texture examinations, the same procedures as those described for copper and brass were followed. The random intensity was measured from a fully austenitized powder prepared from the same steel under investigation.

\section{RESULTS AND DISCUSSION}

\section{Electrolytic copper and 70-30 brass}

For rolling schedule $\mathrm{A}$, the (111) pole figures determined from the specimens of electrolytic copper and of 70-30 brass after $40 \%$ reduction in thickness (from 6.0 to $3.6 \mathrm{~mm}$ ) by rolling in $\mathrm{RD}_{1}$, then $40 \%$ reduction (from 3.6 to $2.2 \mathrm{~mm}$ ) in $\mathrm{RD}_{2}$, are shown in Figure 4 . The textures are essentially similar, having the $\{110\}\langle 223\rangle$ as the main texture with the weaker components $\{520\}\langle 001\rangle$ and $\{110\}\langle 001\rangle$ as the orientation spreads. It can also be noticed that even the total strains in each of the two rolling directions were equal, the texture developed in the last deformation (rolling in the direction $\mathrm{RD}_{2}$ ) was more prominent. This effect in cross-rolling was recognized many years ago by Wassermann (1938), and it was described by Barrett (1952) as that, when only one change of rolling direction is used, the one used last has a somewhat greater influence on the texture if the percentage is more than three-fourths that of the first rolling. In such cases, the predominating range of scatter is around the second rolling direction. The present observation, and more of a similar nature to be presented later (after a higher total 

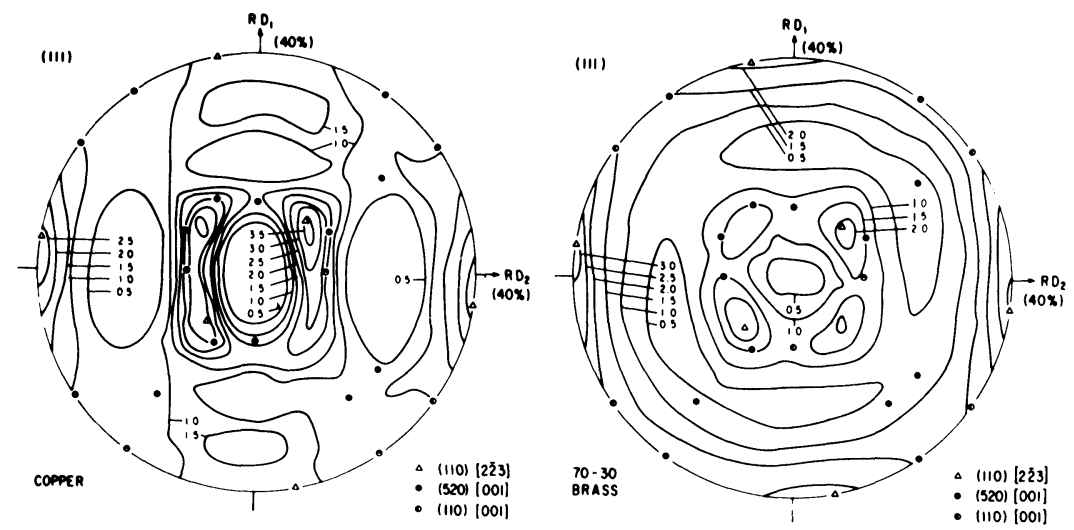

Figure 4 (111) Pole figures showing cross rolling textures of electrolytic copper and $70-30$ brass after $40 \%$ reduction in $\mathrm{RD}_{1}$, then $40 \%$ reduction in $\mathrm{RD}_{2}$.

reduction, Figure 6) are in confirmation with Wassermann's early discoveries.

Following these $40 \%$ reductions in $\mathrm{RD}_{1}$ then in $\mathrm{RD}_{2}$, an additional reduction of $50 \%$ (from 2.2 to $1.1 \mathrm{~mm}$ ) was given to the specimens by rolling in $\mathrm{RD}_{1}$. The textures developed at this stage were examined, and they are shown in Figure 5. As to be expected,
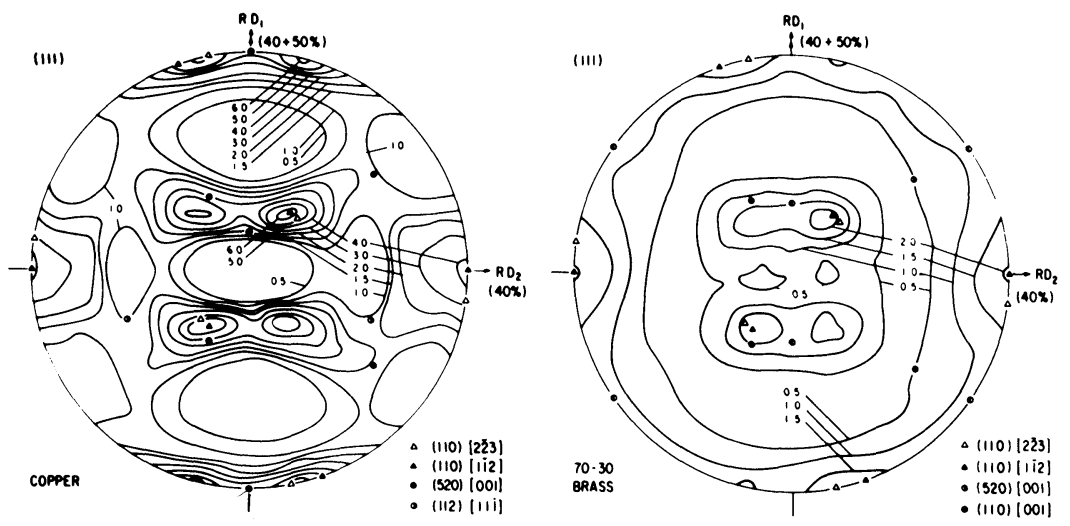

Figure 5 (111) Pole figures showing cross rolling textures of electrolytic copper and 70-30 brass after an additional reduction of $50 \%$ in $\mathrm{RD}_{1}$ following reductions described in Figure 4. 
these pole figures show more prominent features characteristic of straight rolling in $\mathrm{RD}_{1}$. In terms of ideal orientations, these pole figures can be recognized by the presence of texture components and orientation spreads that are characteristic of the copper-type and of the brass-type, corresponding to the material of the specimen. For example, in both copper and brass specimens, the $\{110\}\langle 112\rangle$ components, characteristic of the straight rolling texture in both materials, were developed in addition to the cross rolling textures of the $\{110\}\langle 223\rangle$ major components and the $\{520\}\langle 001\rangle$ spreads. Besides, the $\{112\}\langle 111\rangle$ and the $\{110\}\langle 001\rangle$ orientations, which are characteristic of the copper-type and the brass-type textures, respectively, were also developed in the corresponding specimens after the additional $50 \%$ rolling in $\mathrm{RD}_{1}$. All these observations appear to be consistent with the two types of rolling textures, which are developed only in straight rolling deformation.

Figure 6 shows the cross-rolling textures of the electrolytic copper and of the 70-30 brass after the cross-rolling deformation was completed by rolling additional reduction of $50 \%$ in $\mathrm{RD}_{2}$ (from 1.1 to $0.55 \mathrm{~mm}$ ). As can be noted from these pole figures that the textures of both copper and brass after approximately $91 \%$ reduction by cross rolling are very similar. They can be described by the
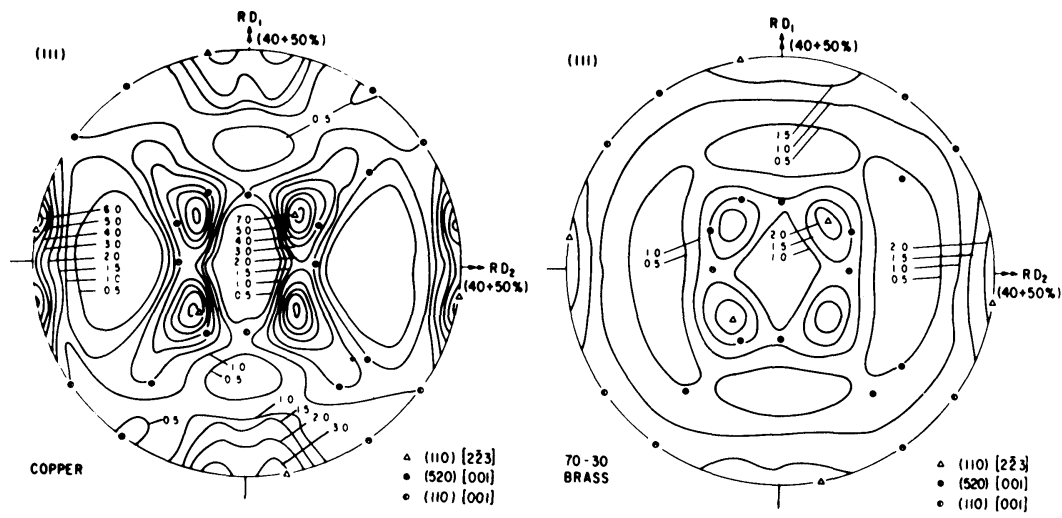

Figure 6 (111) Pole figures showing cross rolling textures of electrolytic copper and 70-30 brass after an additional reduction of $50 \%$ in $\mathrm{RD}_{2}$ following reductions given in Figure 5. 

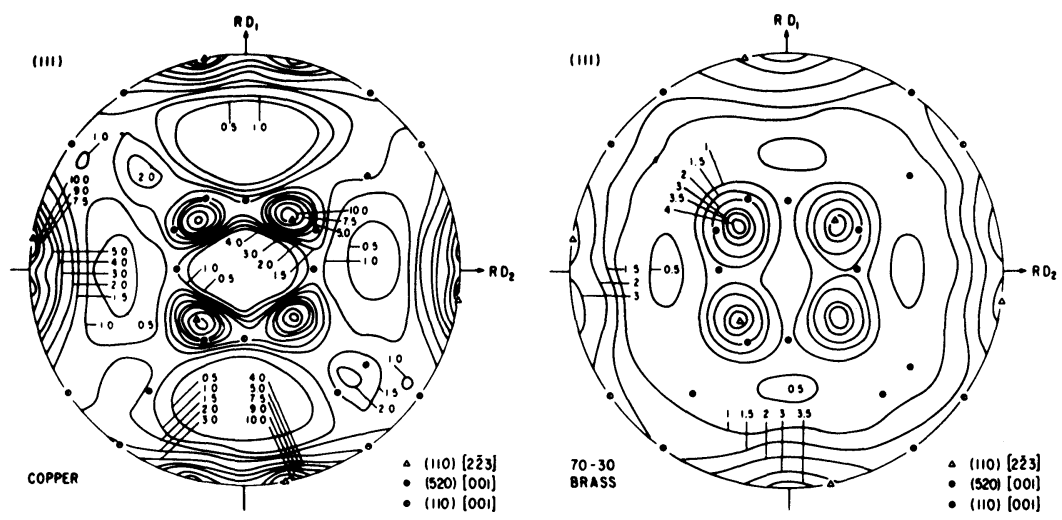

Figure 7 (111) Pole figures showing cross rolling textures of electrolytic copper and 70-30 brass after $90 \%$ reduction in thickness according to rolling schedule B.

same ideal orientations: $\{110\}\langle 223\rangle,\{520\}\langle 001\rangle$, and $\{110\}\langle 001\rangle$. Note that in the copper specimen the $\{112\}\langle 111\rangle$ components, which were produced by the unbalanced rolling in $\mathrm{RD}_{1}$ (Figure 5), were no longer detected in the texture after cross rolling in $\mathrm{RD}_{2}$ (Figure 6). It can also be noted from Figure 6 that the orientation scatter in both copper and brass is more prominent around the second rolling direction $\left(\mathrm{RD}_{2}\right)$ as the axis of scatter than around the first folling direction $\left(\mathrm{RD}_{1}\right)$. This is, again, in agreement with the early findings of Wassermann (1938).
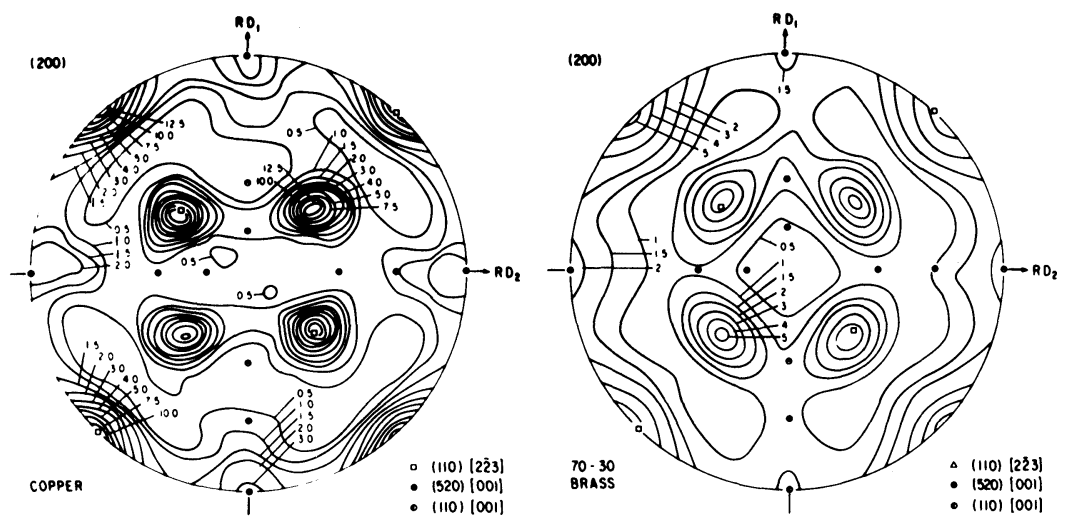

Figure 8 (200) Pole figures of the same specimens used in Figure 7. 


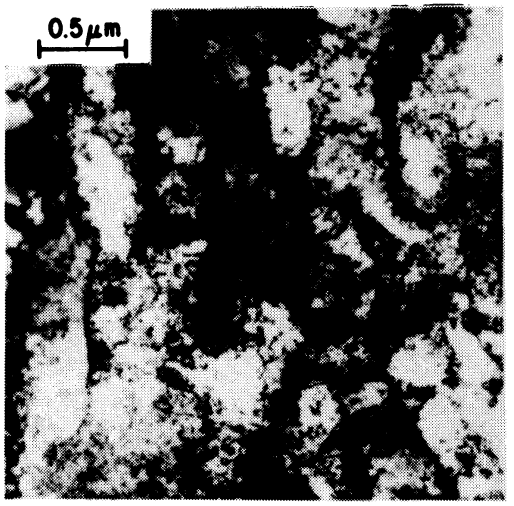

Copper

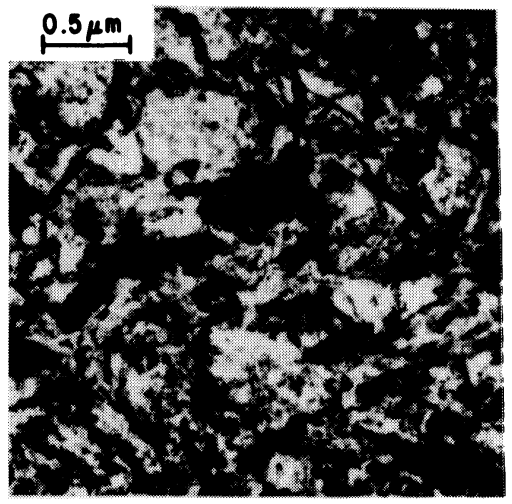

70-30 Brass

Figure 9 Transmission electron microstructure of electrolytic copper and 70-30 brass after cross rolling reduction of $90 \%$ according to rolling schedule $\mathrm{B}$. Thin foil specimen parallel to rolling plane.

The cross rolling textures of electrolytic copper and of 70-30 brass after $90 \%$ reduction in thickness according to rolling schedule $\mathrm{B}$ are shown in Figure 7 and Figure 8 for their (111) and (200) pole figures, respectively. The major features of these textures are quite similar, which can be described by the ideal orientations $\{110\}\langle 223\rangle,\{520\}\langle 001\rangle$, and $\{110\}\langle 001\rangle$. The cross rolling texture

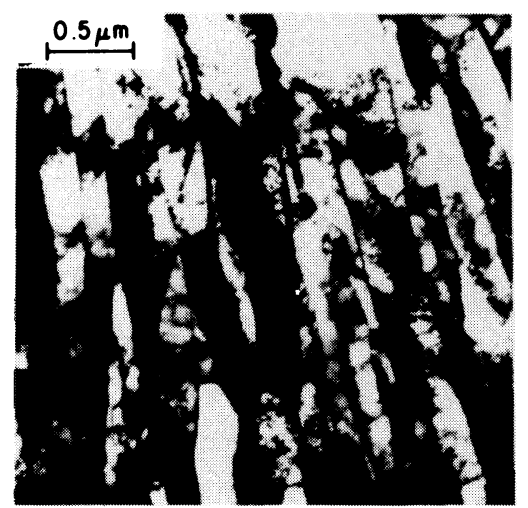

Copper

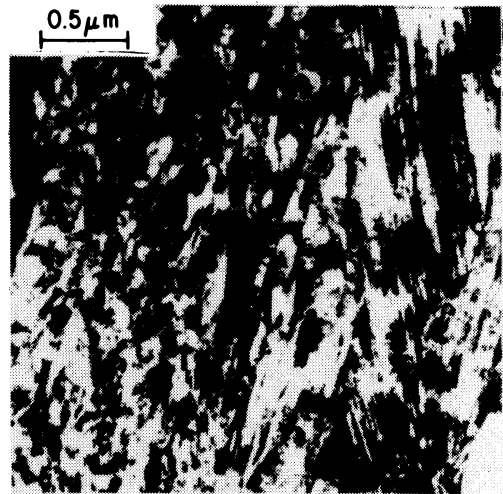

70-30 Brass

Figure 10 Transmission electron microstructure of the same specimens used in Figure 9. Thin foil specimen parallel to longitudinal cross section. 
of copper was studied earlier by Merlini and Beck (1953). The present results are in excellent agreement with theirs. As has been observed previously ( $\mathrm{Hu}$ et al., 1950; $\mathrm{Hu}$ and Goodman, 1963; Goodman and $\mathrm{Hu}, 1968$ ), the intensities of the brass-type texture are always considerably lower than those of the copper-type texture for specimens deformed to the same degree. This may be related to the more fragmented microstructures of the deformed specimens with low stacking-fault energies. The microstructures of the cross rolled specimens of copper and brass rolled according to schedule B are shown in Figure 9 (section parallel to rolling plane) and in Figure 10 (longitudinal cross section).

\section{Type 304 austenitic stainless steel}

Exactly similar studies were conducted with a type 304 austenitic stainless steel rolled at $700^{\circ} \mathrm{C}$ and $200^{\circ} \mathrm{C}$. The results were quite similar to those shown for the electrolytic copper and the 70-30 brass. For brevity, only those results obtained from specimens rolled according to schedule $\mathrm{B}$ are presented here in Figure 11 for the (111) pole figures, and in Figure 12 for the (200) pole figures. The similarity between Figures 7 and 11 and between Figures 8 and 12 are, indeed, striking.
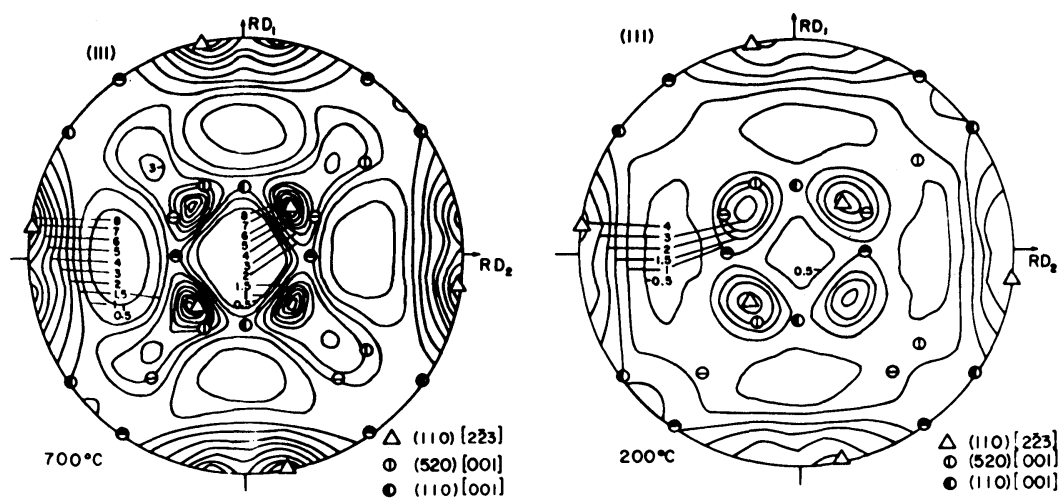

Figure 11 (111) Pole figures showing cross rolling textures of type 304 stainless steel after $90 \%$ reduction by isothermal cross rolling at $700^{\circ} \mathrm{C}$ and at $200^{\circ} \mathrm{C}$, according to rolling schedule $\mathrm{B}$. 

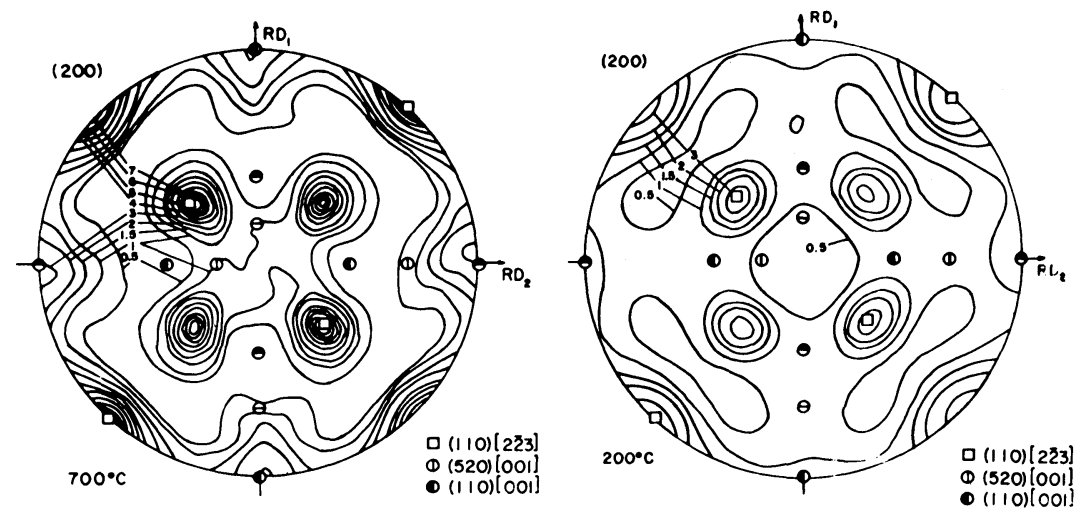

Figure 12 (200) Pole figures of the same specimens used in Figure 11.

\section{SUMMARY AND CONCLUSION}

To further test the mechanical twinning and deformation faulting mechanism for texture transition from the copper-type to the brass-type in rolled fcc metals, a critical experiment has been conducted. The idea was to employ cross rolling to prevent from occurring, or to nullify, the mechanical twinning and deformation faulting process on the $\{112\}\langle 111\rangle$ components in the rolling texture. As a consequence, the cross rolling textures for both high-SFE and low-SFE materials should be essentially the same. Results from carefully conducted experiments with electrolytic copper and 70-30 brass, and with type 304 stainless steel cross-rolled at $700^{\circ} \mathrm{C}$ and $200^{\circ} \mathrm{C}$, confirmed this expectation. These observations are consistent with the mechanical twinning mechanism for texture transition as proposed by Wassermann.

\section{Acknowledgement}

The preparation of this paper is supported by a grant of the National Science Foundation of USA, DMR-8614903.

\section{References}

Barrett, C. S. (1952). Structure of Metals, 2nd ed., McGraw-Hill, New York, p. 478. Goodman, S. R. and Hu, H. (1964). Trans. Met. Soc. AIME, 230, 1413. 
Goodman, S. R. and Hu, H. (1968). Trans. Met. Soc. AIME, 242, 88.

Hu, H., Sperry, P. R. and Beck, P. A. (1950). Trans. AIME, 21, 420.

Hu, H. and Cline, R. S. (1961). J. Appl. Phys., 32, 760.

Hu, H., Cline, R. S. and Goodman, S. R. (1961). J. Appl. Phys., 32, 1392.

Hu, H. and Goodman, S. R. (1963). Trans. Met. Soc. AIME, 227, 627.

$\mathrm{Hu}, \mathrm{H}$., Cline, R. S. and Goodman, S. R. (1966). in Recrystallization, Grain Growth, and Textures, ed. H. Margolin, ASM, Metals Park, OH, p. 295.

Merlini, A. and Beck, P. A. (1953). Acta Met., 1, 598.

Merlini, A. and Beck, P. A. (1955). Trans. AIME, 203, 385.

Schmidt, U. and Lücke, K. (1979). Texture Cryst. Sol., 3, 85.

Wassermann, G. (1938). Z. Metallkunde, 30, Sonderheft Vorträge Hauptversammlung, p. 53.

Wassermann, G. (1963). Z. Metallkunde, 54, 61. 